\title{
2006-1087: GRADUATE STUDENTS AS CO-INSTRUCTORS FOR AN UNDERGRADUATE COURSE: IMPLEMENTATION AND ASSESSMENT
}

\section{Barath Baburao, Tennessee Technological University}

Barath Baburao is currently working on his Ph.D degree in Chemical Engineering at the Tennessee Technological University. His research deals with thermodynamic modeling of aqueous hydrogen fluoride mixtures. He received his B.Tech degree from Annamalai University (India) and his MS degree from Tennessee Technological University.

\section{Donald Visco, Tennessee Technological University}

Donald P. Visco, Jr. is an Associate Professor of Chemical Engineering and Undergraduate Program Coordinator at Tennessee Technological University. He received his $\mathrm{Ph}$. D. in 1999 from the University at Buffalo, SUNY. His research focuses on molecular design for the chemical process and pharmaceutical industries.

\section{Saravanan Swaminathan, Tennessee Technological University}

Saravanan Swaminathan is currently working on his Ph.D degree in Chemical Engineering at the Tennessee Technological University. His research deals with modeling the solubility of small molecules in polymers. He received his B.Tech degree from University of Madras (India) and his MS degree from Tennessee Technological University. 


\title{
Graduate Students as Co-Instructors for an Undergraduate Course: Implementation and Assessment
}

\begin{abstract}
$\underline{\text { Abstract }}$
This work suggests one method to fully expose graduate students to the demands of teaching an undergraduate course under the supervision of a full-time faculty member. The students, called co-instructors, interact with the supervisor on various levels from course design to the grading schemes. Based on the feed back received from the students, it was concluded that this type of interaction provided a useful learning experience for both the undergraduate students and the co-instructors.
\end{abstract}

\section{$\underline{\text { Introduction }}$}

The primary purpose of an engineering college, especially at the undergraduate level, is to provide effective instruction in subject matter through the stimulation and motivation of students ${ }^{[1]}$. Accordingly, it makes sense that those selected to teach undergraduate students should be trained properly for this function. Unfortunately, while most candidates applying for openings have little teaching experience, the institutions that are looking to hire prospective faculty expect their candidates to be "teaching ready"[2]. Adding to this problem is that the teaching experience that graduate students receive is quite different across the nation. For example, some graduate students are just used to grade homework and examinations, while others run homework recitations and a third group handles the laboratory. All of these experiences are quite unique and, at some level, a newly-hired faculty member is expected to be proficient in all of these areas.

The status and nature of training graduate students for teaching is itself a topic of its own right. ${ }^{[3]}$ There have been several suggestions for training doctoral-level candidates for teaching. However, in the engineering arena, most of the efforts concentrate on training graduate teaching assistants (TA) in aiding the full-time faculty during a particular course, as has been previously mentioned. A unique way to address this problem has been put forth very recently by both Purdue University and Virginia Tech ${ }^{[4]}$. At each of these institutions, a graduate student can enroll in an Engineering Education program and receive their $\mathrm{Ph}$. D. in this area. Such students are exposed to every aspect of engineering education from educational principles to various teaching methods. However, these students are not being trained in a so-called "technical area" within their discipline and, hence, it is unknown at this point how effective such training will be in landing a tenuretrack faculty position. Another way to educate graduate students who plan to enter academia is through a formal course during their graduate studies. Universities such as South Carolina and West Virginia offer these classes as an elective course in their respective Chemical Engineering departments. There are also TA instructional programs that are provided in the form of teaching seminars, workshops, language tutorials for newly appointed international TAs, etc ${ }^{[5]}$. Additionally, there are also programs such as Preparing Future Faculty (PFF) at the University of Cincinnati, whose goal is to 
transform the way the aspiring faculty members prepare for their careers. Though this initiative is a cluster of 295 participating institutions, the disciplines primarily involved are in arts and sciences and the participation of the engineering discipline is meager ${ }^{[6]}$. Finally, students can participate in American Society of Engineering Education (ASEE) meetings, either at the national, sectional or local levels (re: student chapters) to be exposed to issues of interest to faculty members concerning teaching, or read ASEEsponsored journals.

While many of the approaches above have obvious positives and negatives, the overwhelming majority of graduate students still receive their information about teaching from the work that they perform as a teaching assistant. To this end, we have developed an approach that completely integrates a teaching assistant into an undergraduate course above and beyond what is normally done. This has been performed during the Spring 2005 semester at Tennessee Tech University in the senior-level Process Dynamics and Control course in the Department of Chemical Engineering. Two graduate students served as co-instructors (CI) for this course which was supervised by a full-time faculty member (FM).

This paper sets up as follows. First, we discuss the selection of the CI and the pre-class preparation required. Next, we comment on how the CI was integrated into all class activities. Finally, we provide an assessment of this approach in terms of a survey given to the undergraduate students who were taking this class.

\section{Co-Instructor Preparation}

It must be noted at this point that the approach we have used here is not applicable for all students (and faculty, for that matter) and all courses. Hence, potential CIs must be chosen according to two minimal, yet necessary, criteria. First, the CI must have taken the class already (or its equivalent) at some point during their career. Second, and most important, is that the student must be interested in teaching with, perhaps, an eye towards an academic career.

Once the student is chosen, the CI should meet with the FM prior to the beginning of the semester to discuss their involvement with the course material. All the materials (course texts, references etc.) that are available to the FM should be provided to the CI. It is also essential at this point to convey to the CI that he/she shares a significant responsibility in all aspects of the course, from developing and delivering the course material to preparing and grading homework and examinations. However, while much freedom is to be provided to the $\mathrm{CI}$, everyone (the $\mathrm{CI}$, the faculty and the undergraduate students) needs to know that the FM is in charge of the class and, ultimately, responsible for all aspects of the class. Hence, the FM needs to be kept in the loop in all correspondence (be it individual meetings with a student and the CI or any emails that are exchanged).

In addition to discussing course content prior to the beginning of the semester, the CI should share with the FM their teaching philosophy, if one exists. At this point, the FM 
can provide reading materials on important pedagogy or methodologies tentatively planned for the class, such as active learning or team-based approaches. The CI is encouraged to suggest and/or implement different approaches than the standard (re: lecture) where applicable.

At Tennessee Tech, it is required that students receive a syllabus during the first day of class. Hence, having the CI design the course syllabus is an effective way to plan out the semester and uncover what, ultimately, is to be done during the semester. To this end, instructional objectives were identified for the course and what was to be done in each class meeting period was planned out, which included when examinations and laboratories were to be scheduled. This was performed prior to the beginning of the semester. Once this was completed, the material to be covered was distributed, somewhat evenly, between the CI and the FM. Except for the initial few class meetings that the FM set aside to introduce the major course concepts, priority was given to the CI to pick his/her own concepts to deliver to the class.

\section{Informational Meetings}

A key component of the approach presented here is the enforcement of individual meetings between the CI and the FM to discuss all activities associated with the course. Accordingly, a weekly meeting time was set up to discuss all relevant aspects of the course, such as feedback on the previous week, plans for the upcoming week, as well as assignments and examinations. The latter will be presented in more detail below. Note that in addition to these weekly meetings, the FM and the CI meet ten minutes prior to the beginning of any class in order to briefly review the plan for that day as well as discuss any unforeseen issues that have arisen.

\section{$\underline{\text { The First Few Class Sessions }}$}

In our approach, the first few class periods were handled by the FM not only to provide an overview of the course, but to discuss the role of the CI in the class. Since undergraduate students normally have had a specific interaction with a TA, their mindset on the role of a TA is set. Thus, it is important at the earliest stages of the class to emphasize that the CI is not a TA and, in fact, shares in all aspects of running the course. While most students do not appreciate this subtlety immediately, it becomes more apparent when the CI runs the class for several sessions in a row, generates assignments and answers questions in class or during office hours.

Since the undergraduate students know a good deal, normally, about the faculty but not much about graduate students, a way to 'bridge this gap' is to provide information to the students about the CI. To this end, the CI provided a short autobiography (attached to the syllabus) and required the same of each student in the class. Additionally, the CI took digital pictures of the students during the first day in order to learn the names of each student. Thus, when the CI met with a student or called on someone in class, they could 
call the student by name. Such an endeavor helps distinguish the CI from a TA who was filling in for a faculty member when he/she is out of town.

\section{Teaching Methods Employed}

Lecturing is the most popular and efficient, time-wise, teaching method that one can employ. While the effectiveness of lecturing, when measuring material retention, pales in comparison to other, more active approaches, we decided to use lecturing throughout this course since the CI had only been exposed to that technique. However, while using the lecture-style as a foundation, we employed team-approaches and active techniques throughout the semester. Those times, when utilized, are discussed in the next section.

\section{$\underline{\text { In-Class Assignments }}$}

Teams of four or five members were formed during the initial part of the class and were determined by the FM who was quite familiar with the abilities and personalities of the students, though several other methods exist to formulate teams ${ }^{[7-11]}$. At least once per week, an in-class assignment was given and worked on by the team. During this time, the CI and the FM walked around the room and interacted with the teams to check on their progress and answer any questions. Note that the in-class assignments were designed by the CI and approved by the FM prior to use in the classroom.

\section{$\underline{\text { Role of the Faculty Mentor During Class }}$}

When the FM is running a particular class, the CI sits in the back of the room and follows along in his/her notes. When the CI is running the class, likewise the FM is in the back of the class to observe the performance of the CI. During the class, if the FM's input is warranted, the FM can interrupt the class. This should not be done often and only when required (i.e. there is a conceptual error on the part of the CI, etc.) After the class concludes, the FM can discuss with the CI any issues that arose during the class that required immediate feedback or, when issues are minor, they can wait until the weekly meetings.

\section{$\underline{\text { Homework }}$}

Each week, a homework assignment was developed by the CI and shared with the FM at their weekly meeting. The CI was introduced and trained to design the homework questions based on different levels of Bloom's taxonomy ${ }^{[12]}$. Every question in the assignment is specified for appropriate levels of Bloom's taxonomy. The CI was provided with the assignments from the previous year and was encouraged to use them as a reference to design new assignments. The CI was also allowed to design the assignments from various sources other than the text book and the provided reference material. All of the questions on the assignments were solved prior to distribution to the students so that it was confirmed that the problem was at a proper level and addressed a particular concept or concepts in the desired way. 


\section{Quizzes}

Quizzes were used in this course to test conceptual understanding in between examinations. The CI was given the freedom to use previous years' quizzes or to design his/her own. The basic format for all of the quizzes but the last one were the same: short answer or multiple choice problems that took about 15 minutes in total. After taking the first quiz, the students were required to collect the quiz from the CI in his/her office. In this way, the student can develop a rapport with the $\mathrm{CI}$ as well as eliminate the excuse that they "didn't know where his/her office was" when questioned on whether they have talked to the $\mathrm{CI}$ about a particular issue in the class.

During the last quiz, the CI developed a "team quiz". In this format, the students in a team received a list of multiple choice questions with no answers and were not allowed to write anything down nor could they consult their notes or text Each team received a different set of questions and the team discussed the questions and potential answers for 10 minutes. After this, each team member received an individual quiz but now the quiz contained the multiple choice answers. Anecdotal feedback on this exercise was quite positive from the students.

\section{Examinations}

In designing the exams, the CI was trained to frame the questions based on the instructional objectives that were provided to the students on the syllabus. In this course, three exams were conducted including the final comprehensive examination. The exams were designed and graded by the CI with approval of both the exam questions and grading scheme done by the FM. Note that the first draft of first examination developed by the CI took the CI 45 minutes to complete, though the exam time was only 55 minutes. It was at this point where the CI learned about timing heuristics used in generating exam questions. Thus, the CI modified the questions (both complexity and number) so that he/she completed the exam in around 20 minutes.

\section{Laboratory}

The CI was charged to construct and closely-relate the concepts discussed in class to a laboratory experience. The topics chosen for these exercises were the ones that are important for an undergraduate student to form (i) a 'bigger picture' of the course and (ii) to familiarize oneself with the tools this course can provide when the student performs a hands-on experiment. In the course, simulation was used to provide illustrations of phenomena that are not easily visualized, such as level-control in gravity drained tanks, temperature-control of a jacketed reactor, etc. For simulation purposes, the process control software used was 'ControlStation $4.7^{\prime}{ }^{[13]}$. Five lab assignments were designed and conducted by the CI around the ControlStation software. The software lets the students design, implement and test control solution using computer interface, much like the one they would find in industrial practice. Note that in each case, the FM guided and approved each of these laboratory assignments. 
In addition to the virtual experiments conducted for this course, a hands-on experiment was also designed and conducted by the CI. Each team performed the experiment outside of the normal class meeting time. This exercise not only related to the various concepts covered in the course through experimentation, but also allowed the students to experience the difference between simulation software and a hands-on experiment.

\section{Course Projects}

Each team was required to complete a course project by the end of the semester. The projects included a presentation as well as a written report. In order to assess the presentations and the projects, the CI developed (with input and approval of the students and the FM) an assessment form that was to be used by the CI, the FM and the students. Students were given a deadline (two days after the presentation date) to make some changes to their report to address the questions raised by their fellow-students and the instructors.

\section{$\underline{\text { CI Evaluation and Assessment Results }}$}

Since the FM was the individual to be evaluated during required end-of-semester assessments, a special assessment was performed to determine the efficacy of integrating the graduate student into the course. The CI determined, with approval of the FM, what areas were to be assessed and, in fact, the development of this assessment proved educational for the $\mathrm{CI}$ in its own right.

The assessment form contained 18 questions that covered six areas: (1) lectures, (2) labs, (3) organization, (4) student interaction, (5) in-class activities and (6) assignments/testing. The students were asked to assign a score for each question from 1 to 9 , with 9 being the best. The students were given this assessment form during the last day of class and were asked to turn it in during the Final Exam. Of 21 students, 14 submitted completed forms, the results of which are presented in Table 1. Also, since two CIs were used in this course, the scores (see Table 1) presented are an average of both CIs. Note that there was ample area provided to write comments in, per question; a sampling of which are given in Table 2.

\section{Assessment Discussion}

Overall, it can be seen that the undergraduate students rated the CI as 'above average'. In particular, the best area was deemed Student Interaction. As can be inferred from Comment \#2 of Table 2, when students (even if they are graduate students) teach other students, this apparently creates less trepidation from the undergraduate student perspective. Additionally, graduate students are likely to keep similar hours to that of undergraduate students (evenings, late nights and weekends) thus making them appear more accessible relative to a faculty member that normally have more burdens on their time. The other vital aspect of the feedback was the 'Labs' section. The undergraduate students found that the virtual/real laboratory experiments were interesting and were 
satisfied with the fact that the CI was able to relate the lab to the lectures and was amply knowledgeable about it.

Table 1: CI evaluation forms results with standard deviation in parentheses. $1 \rightarrow 3$ below average, $4 \rightarrow 6$ average, $7 \rightarrow 9$ above average. The average was based on the feedback received from 14 of the 21 students in the class, for both instructors.

\begin{tabular}{|l|l|}
\hline Assessment Question & Average \\
\hline Lectures & \\
\hline How would you rate the subject knowledge of the instructor? & $8.1(0.8)$ \\
\hline How would you rate the communication skills of the instructor? & $7.5(0.9)$ \\
\hline How would you rate the instructors' use of board or other visual aids? & $7.1(0.4)$ \\
\hline How would you rate the instructors' lecture style? & $7.4(0.9)$ \\
\hline & \\
\hline Labs & \\
\hline How would you rate the subject knowledge of the instructor when conducting the lab? & $8.3(0.6)$ \\
\hline How do you think the instructor connected the lab to the class material? & $8.0(0.9)$ \\
\hline & \\
\hline Organization & \\
\hline How well do you think the instructor was prepared ahead of the lecture? & $8.1(0.7)$ \\
\hline How would you rate instructors' logical progression in delivering a concept? & $7.3(0.3)$ \\
\hline How would you rate the instructors' time management during the lecture? & $8.0(0.9)$ \\
\hline & \\
\hline Student Interaction & $8.2(0.8)$ \\
\hline How well do you think the instructor encouraged the student involvement during the lecture? & $8.8(0.4)$ \\
\hline How would you rate the accessibility of the instructor on and off lecture hours? & $8.6(0.6)$ \\
\hline How well do you think instructor showed interest in individual students? & \\
\hline & $7.6(0.5)$ \\
\hline In-Class Activities & $7.9(0.6)$ \\
\hline How well do you think the instructor organized the in-class activities? & \\
\hline $\begin{array}{l}\text { How well do you think the instructor used the group activities pertaining to the course } \\
\text { material? }\end{array}$ & $7.7(0.2)$ \\
\hline & $7.0(0.6)$ \\
\hline Assignment/Testing & $8.8(0.4)$ \\
\hline $\begin{array}{l}\text { How well do you think the instructor designed and connected the assignments, quizzes and } \\
\text { exams to the concepts delivered in the lectures? } \\
\text { How well do you think the instructor designed the assignments, quizzes and exams based on } \\
\text { work load and time constraints of the students? }\end{array}$ \\
\hline How would you rate the promptness of the instructor in returning the graded material? \\
\hline
\end{tabular}


Table 2: A sample of comments taken from completed assessment forms.

\begin{tabular}{|l|l|}
\hline Number & Student Comments \\
\hline 1 & $\begin{array}{l}\text { "When you first announced, that the CI would be taking a more significant role than the } \\
\text { usual role in class, I was disappointed.....However, as the course proceeded, I have } \\
\text { been extremely impressed with the overall package of the course and consider this to be } \\
\text { a positive learning experience" }\end{array}$ \\
\hline 2 & $\begin{array}{l}\text { "Your ability to interact with students really improved my learning experience, because } \\
\text { I had no uneasiness about asking questions. This is the greatest asset that a graduate } \\
\text { student can have over a full time professor" }\end{array}$ \\
\hline 3 & $\begin{array}{l}\text { "You greatly improved over the progression of the semester from the first lecture" } \\
\text { "I can't remember a time when the CI was not available for help" }\end{array}$ \\
\hline 5 & $\begin{array}{l}\text { "The CI genuinely care that the students completely understand the concept... and put } \\
\text { forth significant effort to listen, understand, and communicate in general...the CI } \\
\text { appear to work hard at developing ways to enhance student learning and have }\end{array}$ \\
\hline 6 & $\begin{array}{l}\text { "You did a wonderful job, I know there is a lot of information to cover, but if you could } \\
\text { go slower when writing on the board that would be great" }\end{array}$ \\
\hline 7 & $\begin{array}{l}\text { "Don't get flustered when students ask questions, you know what you are talking about" } \\
\text { "Triminating or time-constraining material of lesser importance" }\end{array}$ \\
\hline 8 &
\end{tabular}

\section{$\underline{\text { Conclusions }}$}

In this work we presented an integrated approach of using a graduate student as a coinstructor in an undergraduate classroom. Such a technique is above and beyond what is normally expected of a "traditional" teaching assistant. The CI was involved in every single aspect of the course, from the selection of the concepts to be taught to the development of each assignment. The faculty member's role was in an advisory capacity in many instances, though not exclusively. The FM led about an equal percentage of all class periods which was useful in demonstrating to the class that this was truly an apprenticeship relationship. Based on the feedback received from the students during a formalized assessment, the students generally agreed that the CI involvement turned out to be a positive experience for all involved. Note that the average student grade did not change significantly from the previous year (taught by the FM alone) and the current year (taught by the FM and the CI), moving from a 3.07 GPA to a 3.09 GPA.

Note that mentoring a graduate student inside an undergraduate classroom in Engineering (even Chemical Engineering), is not novel. Michigan State University has done this in their College Teaching Certificate (CTC) program ${ }^{[14]}$ which is much more exhaustive than what has been described here in this work. However with respect to solely in-class experience, in the CTC program, a graduate student spends between 2 and 4 weeks involved with a particular class while in our work, the graduate student is used over the entire 14 week semester. We feel that our approach provides the graduate student with a 
more authentic in-class experience since, during the very first class, the undergraduate students are made aware of the "teaching team" situation. 


\section{$\underline{\text { References }}$}

1. "Report of the Committee on Evaluation of Engineering Education," J. Eng. Ed., September, 25 (1955).

2. Adams. K.A., "What Colleges and Universities Want in New Faculty?" Association of American Colleges and Universities (2002).

3. Davis, S., Kring, J. "A Model for Training and Evaluating Graduate Teaching Assistants", College Student Journal, 35(1), 45 (2001)

4. Katehi, L., K. Banks, H. Diefes-Dux, D. Follman, J. Gaunt, K. Hahgighi, P. K. Imbrie, R. Montgomery, W. Oakes and P. Wankat, "Development of Graduate Programs in Engineering Education," Proceedings of the 2004 American Society for Engineering Education Annual Conference \& Exposition, (2004).

5. Torvi, D.A., "Engineering Graduate Teaching Assistant Instructional Programs: Training Tomorrow's Faculty Members", J. Eng. Ed., 83, 1 (1994).

6. DeNeef, A.L., "The Preparing Future Faculty Program: What Difference Does It Make?" Association of American Colleges and Universities. Number 8, (2002).

7. Wankat, C.P, and S. F. Oreovicz, Teaching Engineering, McGraw Hill, New York, NY (1993).

8. Oakley, B., R. M. Felder, R. Brent and I. Elhajj, "Turning Student Groups into Effective Teams", J. of Student Centered Learning, 2 (1), 9 (2004).

9. Zzkarian, A, and A. Kusiak, "Forming Teams: An Analytical Approach" IIE Transactions, 31 (1), 85 (1999).

10. Obaya, A., "Getting Cooperative Learning" Science Education International, 10(2), 25 (1999).

11. Felder, R.M., D.R. Woods, J. E. Stice and A. Rugarcia. "The Future of Engineering Education II. Teaching Methods That Work", Chem. Eng. Ed., 34 (1), 26 (2000).

12. Bloom, B.S., "Taxonomy of Educational Objectives", New York, NY: Longmans, Green, (1956).

13. Cooper, D.J., D. Dougherty, and R. Rice, "Building Multivariable Process Control Intuition Using Control Station", Chem. Eng. Ed., 37(2), 100 (2003).

14. T. M. Baber, D. Briedis and R. M. Worden, "Teaching and Mentoring Training Programs at Michigan State University: A Doctoral Student's Perspective”, Chem. Eng. Ed., 38(4), 250 (2004). 